\section{On the necessity for growth}

Economists are strongly attached to the concept of economic growth, which presumably they invented. It is defined as the sustained increase of gross domestic product (GDP), another invention of economists. Famously, Sir John Cowperthwaite, Financial Secretary of Hong Kong 1961-1971, refused to track the GDP of the colony - and it prospered during his tenure.

The mechanisms of economic growth are conventionally considered to be growth in the quantity of labour, growth in the quantity of capital, and growth in the sophistication of technology [1-3]. The first two are called "extensive" quantities; the last one is called "intensive", pace the extensive variables that depend on the size of the system in thermodynamics (e.g., energy, entropy) and the intensive variables that do not (e.g., pressure, temperature). The analogy is not exact because the development of technology might well depend on system size [4]. Immense effort goes into analysing growth in order to find its causes, although there is as yet no consensus on that.

In recent years economists have expressed disappointment at persistently low growth in the Western economies. At the same time, growing awareness of the problems of climate change, and the clear association of global warming with economic activity (e.g., world GDP) have made economists rather defensive about the need for growth. Looking at historical data, it is tempting to conclude that by reversing growth, global warming could also be reversed. One problem is, of course, that world population has greatly increased, hence if one wished to revert to the estimated level of world GDP before global warming started to occur (see [5] for some data), GDP per capita would have to be much smaller than it was at that time.

Economists are quick to point that out, and also that encouraging economic growth is the best way to solve, not only the problem of global warming (by fostering technical innovation that could overcome it) but also a range of other problems, hence the best way to achieve the United Nations millennium development goals, which include the eradication of extreme poverty, the improvement of maternal health, and combating malaria and other diseases. One of these goals is to ensure environmental sustainability, which is often demonstrably incompatible with economic growth. According to the "growthmen" [6] (and presumably women too), technical innovation will also enable environmental sustainability to be achieved.

Some economists, notably Cowen [7], argue that economic growth should be an overwhelming societal objective. One might have some reservations because many years ago the idea of wealth being a value, and wealth maximization a social goal, was discussed [8]. Thorough analysis by Dworkin [9], Schmalbeck [10] and doubtless others concluded rather firmly that it was not. Then, as now, an argument in favour of wealth being a value was that it might be the means to adjust society. Dworkin, however, concluded that social wealth was not even a component of value.

A clue to the possible error of promoting economic growth is given by the well-known feature of the reckoning of GDP that measures (such as an obligation to install pollution control equipment in a factory) are generally considered to exert a dampening effect on GDP and, hence, growth. For this reason, "growthmen" are often opposed to environmental protection measures. They forget that the first industrial pollution control measures, notably the scrubbing of hydrochloric acid from the emissions from the manufacture of sodium carbonate by the Leblanc process, which became obligatory after the enactment of the Alkali Act in 1863 in the UK, was highly profitable because the recovered hydrochloric acid could be sold as a valuable by-product [11]. Very possibly each pollution control measure has to be examined on a case-by-case basis to determine the sign of the net effect on GDP, but undoubtedly the introduction of such measures fosters innovation. The whole tenor of the current "green growth" policy is that environmental sustainability does not only that, but also that it can become a source of economic growth [12].

Very often the supposed "cost" of a pollution control measure arises purely because the external diseconomy of the polluting activity is not reckoned [13]. There are signs that this is changing, albeit slowly, with the introduction of more stringent regulations, about which more will be stated below.

My thesis is not, however, that the reasonableness of economic growth could be rescued by better accounting of GDP, but that beyond a certain level, economic growth as generally defined is actually inimical to the development of civilization.

The primary reason for that is the finite amount of space available to us. Land is extremely important to any nation. At least some of the economic success of Hong Kong might be due to its diligent land reclamation. It is estimated that it has thereby increased its land mass by between 6 and 7\%. Furthermore, reclaimed land accommodates almost $30 \%$ of the city's population and $70 \%$ of its commercial activity - it is disproportionately valuable. Table 1 compares the amount of land per unit of GDP for a few countries. It is interesting to note that 
the size of this parameter quite well correlates with the general sense of freedom and opportunity that one has within the country. Within the framework of this crosscountry snapshot comparison, it can be inferred that economic growth diminishes this sense of freedom. The correlation compels further attention to the phenomenon.

Table 1. Land area per unit of economic activity.

\begin{tabular}{lccc}
\hline Country & Land area $/ \mathrm{km}^{2}$ & $\mathrm{GDP}^{a} /$ USD $\times 10^{9}$ & Land $/ G D P^{b}$ \\
\hline France & 643,800 & 2583 & 25 \\
Georgia & 153,910 & 15.16 & 1015 \\
Switzerland & 41,285 & 679 & 6.1 \\
UK & 242,495 & 2622 & 9.3 \\
USA & $9,834,000$ & 19,390 & 51 \\
\hline
\end{tabular}

${ }^{a}$ For 2017

${ }^{b}$ In units of $\mathrm{dm}^{2} / \mathrm{USD}$.

The general problem of economic growth is that it leads to increasing daily unpleasantness of life. This unpleasantness is immediately apprehensible. The growth of motorized traffic, and the proliferation of building sites, are two of the most obvious manifestations- - Zuvielisation". ${ }^{1}$ It can scarcely be denied that such trends have a deleterious effect on motivation and, ultimately, the capacity to innovate. One might add cramped, crowded trains and aeroplanes, a general tendency to lose picturesque traditions, and so forth. Interestingly, although a good deal could be done to alleviate some of the unpleasantness, such as planting trees in profusion around all new buildings, making railway stations aesthetically attractive (such as the Moscow Metro) and the like, typically very little is actually done. Other deleterious aspects of a surfeit of economic growth can be analysed more quantitativelyfor example, the growth in the number of university students [14].

The vital ingredient for innovation is freedom [15]. In a general way, the more one's space is curtailed, the less freedom one has. Unfortunately, so much of what economic growth entails curtails our space and freedom - or is irrelevant to it. An example of the latter is the current craze for LED lamps, for which the motivation is supposed to be their superior electricity-to- light conversion compared with incandescent bulbs. A great deal of innovation goes into these LED lamps - " "an incredibly promising lighting technology" [16]. The energy efficiency is, however, nugatory (except for outdoor lighting), because in winter incandescent bulbs make a valuable contribution to space heating, and in summer one needs much less lighting anyway; even for outdoors, the aesthetic effect of incandescent bulbs is wonderfully attractive, as could be seen in Tbilisi until the early years of this century. ${ }^{2}$

Freedom is usually opposed to bread, or wealth more generally. This has been known at least since Aesop [17]. Perhaps today's innovators in the big, highly commercialized technology companies consider that increased wealth can compensate for loss of freedom. The compensation may be illusory, however-typically increasing wealth brings with it ever-increasing constraints. This too is well known. ${ }^{3}$

Returning to Table 1, its use is for making snapshot comparisons between different countries. Whether, during the past decades and centuries of economic growth, the sense of freedom and opportunity has gradually diminished is a rather difficult historical question. Nor should it be presumed that where countries suffer sudden falls of GDP (as, e.g., Venezuela at present), the sense of freedom increases (in that case it seems to be the opposite).

Undoubtedly the innovator makes extensive use of the fruits of economic growth. He or she doubtless appreciates the speed and convenience of powerful modern laptop computers for calculations. Their availability is thanks to the popularity of computer gaming, which has a far larger market than that of engineers and scientists wishing to do calculations. But they are not indispensable - mainframe computers could be used, albeit less conveniently, if laptops were unavailable. The Internet was initially developed as a means for scientists to communicate with each other but has since grown vastly, thanks to which search engines are extremely valuable tools, completely replacing the traditional library. ${ }^{4}$ At the same time, the convenience of e-mail is significantly compromised by the vast amounts of "junk" mail arriving in one's inbox.

1 This was the title of a picture that for many years hung on a corridor wall in the Institute of Botany of the University of Fribourg, Switzerland.

2 The disappearance of incandescent bulbs from Tbilisi's streetlights is a particularly interesting phenomenon, because it occurred around the time when GDP was strongly increasing. Incandescent bulbs are more expensive to run, hence the country could have increasingly better afforded to run them, but presumably they were perceived as being "inefficient" - the aesthetic aspect was wholly disregarded.

3 The idea is well captured by G.C. Pfeffel's poem Der freie Mann (set to music by Beethoven).

4 The Internet and, more generally, electronic data processing capabilities have been at least partly responsible for the enormous increase in the volume of published scientific literature, which has itself rendered the assistance of electronic searching practically indispensable. 
To recapitulate, the one really indispensable thing for innovation is freedom, and freedom tends to be diminished by economic growth. To be sure, our capabilities of mastery over nature have increased pari passu with economic growth, and this mastery may be essential to enable humankind to overcome exogenous shocks. ${ }^{5}$ Furthermore, it may be that, true to our predatory nature, we can do little to stop ourselves developing ever more sophisticated machines [18], a development that is indissociable from economic growth.

Apart from wealth, the other enemy of innovation is bureaucracy [19]. On the whole, growthmen also tend to be against bureaucracy, associating it with onerous environmental and other regulations. ${ }^{6}$ The challenge here is how to ensure that external diseconomies are properly accounted for in every type of economic activity without innovation- and entrepreneurialism-stifling regulations. Regulation occupies a peculiar place in the general framework of our system of laws, which is indispensable for the harmonious functioning of society. As Philip Wood has pointed out [20], many regulatory bodies are an affront to basic constitutional notions of the separation of powers, because government regulators combine the roles of legislator, executive (monitoring compliance) and judicial tribunal (to punish offences). It is not, therefore, surprising that they have uneasy relationships with both the industries that they are meant to regulate and the sectors of the public that they are meant to protect.

Another absurdity of the growth paradigm is that we end up with production for production's sake [21]. The breathtaking increases in productivity achievable with machinery, especially digital machinery, make it almost inevitable. ${ }^{7}$

If, then, economic growth is actually unstoppable, we can expect that innovation will gradually diminish, ${ }^{8}$ eventually bringing growth to a halt. By then we might be extremely vulnerable to both exogenous and endogenous shocks. This could be a general mechanism for the collapse of civilizations, although as far as we are aware we are the only civilization to have mastered the largescale development of machinery (which may eventually encompass artificial intelligence), hence a different fate may be in store for us.

\section{J.J. RAMSDEN}

\section{References}

1. R.M. Solow, A contribution to the theory of economic growth. Q.J. Econ. 70 (1956) 65-94.

2. J.W. Kendrick, Productivity Trends in the United States. Princeton: University Press (1961).

3. E.F. Denison, Accounting for United States Economic Growth, 1929-1969. Washington DC: Brookings Institution (1974).

4. J.J. Ramsden, The future of cities. Nanotechnol. Perceptions 12 (2016) 63-72.

5. G.C. Holt and J.J. Ramsden, Introduction to global warming. In: Complexity and Security (eds J.J. Ramsden and P.J. Kervalishvili), pp. 147-184. Amsterdam: IOS Press (2008).

6. E. Phelps, The golden rule of accumulation: A fable for growthmen. Am. Econ. Rev. 51 (1961) 638-643.

7. T. Cowen, Stubborn Attachments: A Vision for a Society of Free, Prosperous, and Responsible Individuals. San Francisco: Stripe Press (2018).

8. R.A. Posner, The Economics of Justice. Cambridge, Mass.: Harvard University Press (1981).

9. R.M. Dworkin, Is wealth a value? (review of R.A. Posner's Economic Analysis of Law (2nd edn, 1977). J. Legal Studies 9(1980) 191-226.

10. R. Schmalbeck, The justice of economics: An analysis of wealth maximization as a normative goal (review of ref. 8). Columbia Law Rev. 83 (1983) 488-525.

11. J.J. Ramsden, A.G. Mamalis and N.T. Athanassoulis, The ethics of sustainability. J. Biol. Phys. Chem. 18 (2018) 154-163.

12. The Clean Growth Strategy. Leading the Way to a Low Carbon Future. London: HM Government (2017).

13. E.P. Mishan, The Costs of Economic Growth. London: Staples Press (1967).

14. G.C. Holt, Higher education: a risk too far? Nanotechnol. Perceptions 8 (2012) 139-147.

15. J.J. Ramsden, Freedom to tackle the grand challenges. Nanotechnol. Perceptions 8 (2012) 3-6.

16. M. Jacoby, Tuning phosphors for better white light. C\&EN (10 November 2018) 29-32.

17. Aesop, Freedom Preferred to Security (ed. J.J. Ramsden). Basle: Collegium Basilea (2015) (the fable dates from c. $600 \mathrm{BC}$ ).

18. O. Spengler, Der Mensch und die Technik. Munich: C.H. Beck (1931).

19. L. von Mises, Bureaucracy. Grove City, Pennsylvania: Libertarian Press (1996) (first published in 1944).

20. P.R. Wood, The Fall of the Priests and the Rise of the Lawyers, p. 244. Oxford, UK and Portland, Oregon: Hart Publishing (2016).

21. G. Piel, For the living generation. In: The Science of Science (eds M. Goldsmith and A. Mackay), pp. 56-70. London: Souvenir Press (1964).

\footnotetext{
5 It will doubtless also be pointed out that economic growth is responsible for the anthropogenic part of global warming, which is an endogenous shock.

6 Curiously, growthmen nevertheless seem to be keen on government-funded scientific research.

7 Some forms of economic growth are not directly connected with increased mechanization; e.g., the opening of more Domino's pizza shops; it is, however, doubtful whether this contributes to the raising of gastronomic standards. Other examples of a similar nature will readily come to mind.

8 We assume that endogenous innovation is the main growth driver.
} 